\title{
Rock Burst Mechanics: Insight from Physical and Mathematical Modelling
}

\author{
J. Vacek, J. Vacek, J. Chocholoušová
}

Rock burst processes in mines are studied by many groups active in the field of geomechanics. Physical and mathematical modelling can be used to better understand the phenomena and mechanisms involved in the bursts. In the present paper we describe both physical and mathematical models of a rock burst occurring in a gallery of a coal mine.

For rock bursts (also called bumps) to occur, the rock has to possess certain particular rock burst properties leading to accumulation of energy and the potential to release this energy. Such materials may be brittle, or the rock burst may arise at the interfacial zones of two parts of the rock, which have principally different material properties (e.g. in the Príbram uranium mines).

The solution is based on experimental and mathematical modelling. These two methods have to allow the problem to be studied on the basis of three presumptions:

the solution must be time dependent,

the solution must allow the creation of cracks in the rock mass,

the solution must allow an extrusion of rock into an open space (bump effect).

Keywords: rock burst, bump, mining, rock mechanics, mathematical and physical modelling.

\section{Introduction}

A rock burst is the most dangerous event that can occur during excavation works. Surrounding rock is extruded into an underground open space by a severe force during a rock burst. This event may cause an accident or even the death of mining workers, and it may destroy the excavation space. For this reason, studies of this problem are very important theoretically and for practical applications. See [1], [2], [3], and [7-9].

Sufficiently high pressure at the place of the rock burst is necessary for bump occurrence (usually great depth, but also tectonic pressure) and the rock must be brittle and must have a disposition for bumps (properties that allow the creation of bumps).

For the occurrence of bursts, mining velocity is also a very important factor. In the same conditions if we excavate slowly, we give the rock mass sufficient time to create cracks in the vicinity of the open space. For this reason, the stress concentration next to the excavation falls, and no bump occurs. If mining works proceed rapidly, cracks have no time to occur, and a rock burst appears. This feature is confirmed by old mining experience. For this reason, it is necessary to study this event as a time dependent problem.

Rock bursts were studied for the case of a mine gallery inside a horizontal coal seam. their mechanics and the stress distribution on the top of the seam were studied by mathematical and experimental modelling.

\section{Experimental part}

\subsection{Testing devices}

\subsubsection{Loading cell}

Fig. 1 shows loading cell. It consists of the lower steel tank, which is designed for the horizontal forces caused by the vertical load in araldite specimens. The loading cell is equipped with lucites on its sides, which allow observation of the samples during the tests. The tank is shown in Photo 2. This loading cell models (simulates) the rock mass in the vicinity of the seam. In the loading cell (with dimensions of 160/400/70 mm) we placed two araldite specimens, which model the coal seam.
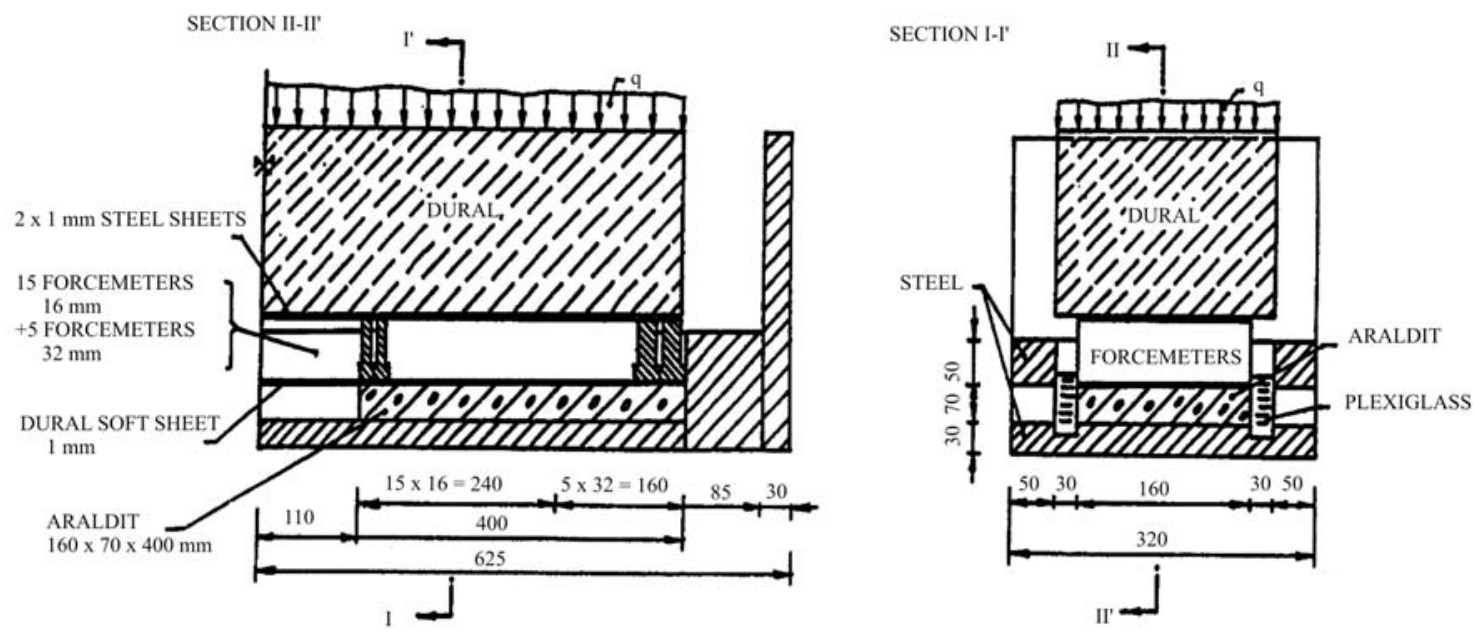

Fig. 1: Scheme of the loading cell 


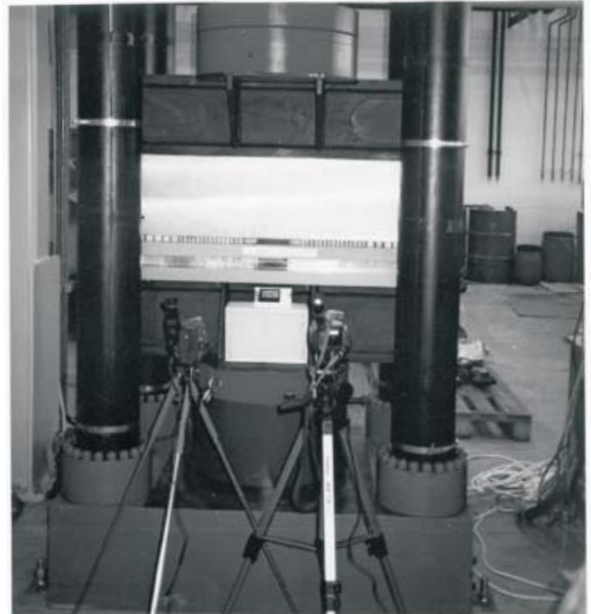

Photo 1: Testing device. Two camcorders recorded the test

The gap between them corresponds to the width of a working gallery in a mine. We observed the mechanism and the history of coal rock bursts. The araldite specimen was covered with a soft duralumin sheet, and force meters were placed on it in the following manner: 5 comparatively thick force meters were placed near its outer edge, and another 15 thinner force meters were placed next to them (see Fig. 1 and Photo 2). In order to embed the force meters properly and to prevent them from tilting, another double steel sheet, $1 \mathrm{~mm}$ thick, was placed over the force meters. A block of duralumin $300 \mathrm{~mm}$ in height was placed over this sheet. This block simulates the handing wall and models the stress distribution similarly to that in reality (see Photo 1). The bedrock was modelled by a steel sheet.

\subsubsection{Force meters}

Photo 2 shows the force meters. The force meters are $160 \mathrm{~mm}$ in length, $68 \mathrm{~mm}$ in height, and 16 or $32 \mathrm{~mm}$ in width. There are 4 strain gauges on each force meter -2 on one side, $30 \mathrm{~mm}$ from the edge of the force meter and 2 on the other side, $60 \mathrm{~mm}$ from the edge of the force meter. These allow us to measure the deformation along its full length.

The data from each force meter was read automatically every 10 seconds by a Brüel \& Kj $\mathrm{r}$ strain gauge bridge, and deposited in a computer. It takes $1,2 \mathrm{~s}$ to read 40 force meters.

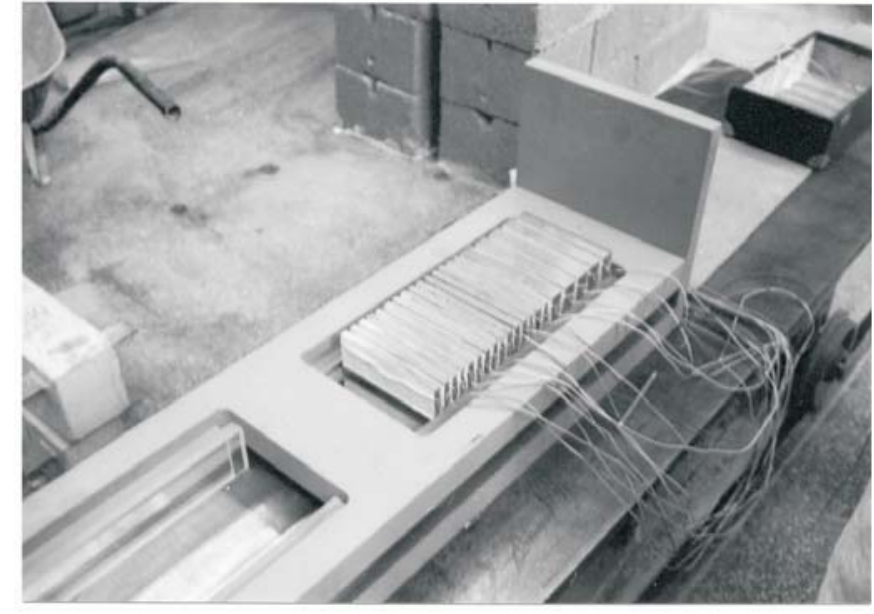

Photo 2: Loading cell. Right with sample and force meters.

\section{1. 3 Conduct of the experiments}

Three tests with various speeds of loading were used during our experiments. The whole system was uniformly loaded with a speed of loading of 50, 240 or $1200 \mathrm{kN} / \mathrm{min}$. In all cases, the total force reached was $6 \mathrm{MN}$ (the maximum force of the testing apparatus), i.e. the total experimental time was 5, 25 and $120 \mathrm{~min}$, respectively. The average load of the araldite samples at the end of the test was $46.875 \mathrm{MPa}$, while the maximum load close to the mine gallery was approximately doubled, see Figures 2 and 3. The force meters can sustain this load without reaching the yield limit of their steel.

The reading frequency on the force meters was $10 \mathrm{~s}$ on a commercial $\mathrm{Br}$ el \& Kjaer bridge. The speed camera/camcorder was equipped with a $2 \mathrm{~s}$ loop tape, i.e. a recording was overwritten after $2 \mathrm{~s}$. After the rock burst, the camera stopped and the last two seconds remained recorded.

The rock burst intensity was proportional to the intensity of the produced sound effect and, more accurately, proportional to the level of decrease in the load force. In the case of the strongest bursts, the force decreased all the way to zero.

\subsection{Some of the results}

More results are given in Ref. [4], [5] and [6].

VW Mean value $-\mathbf{4 1 7 0 / 4 2 6 5} \mathbf{k N}$

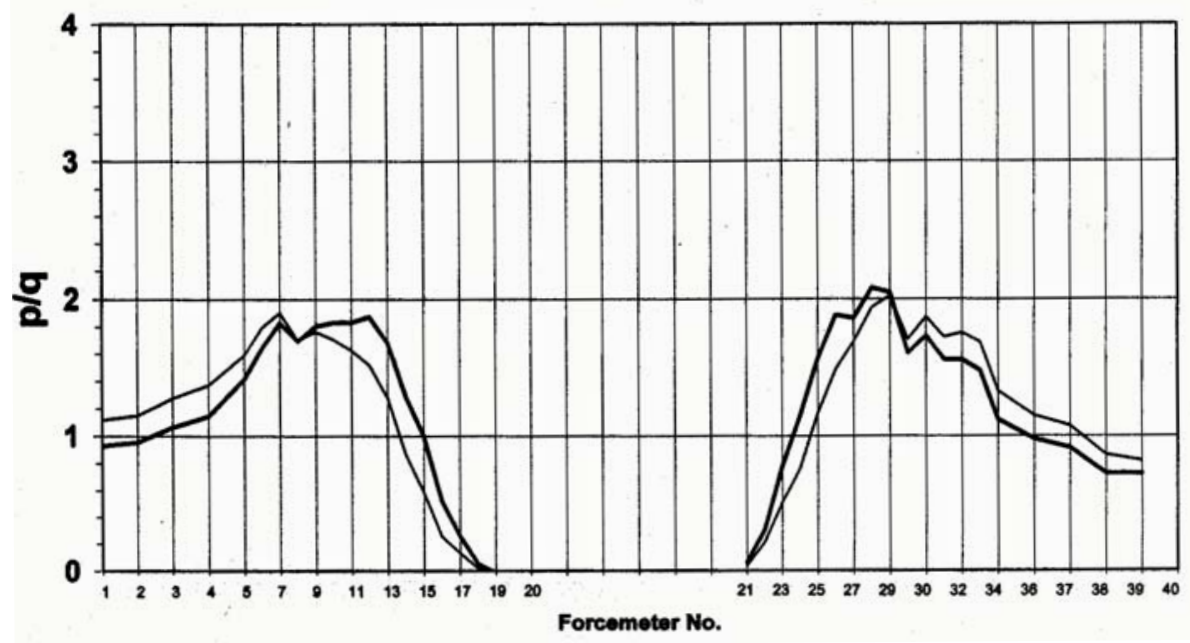

Fig. 2: Mean stress distribution of the coal seam loading before (thick line) and after a bump. The force is 4170-4265. 
VW 21

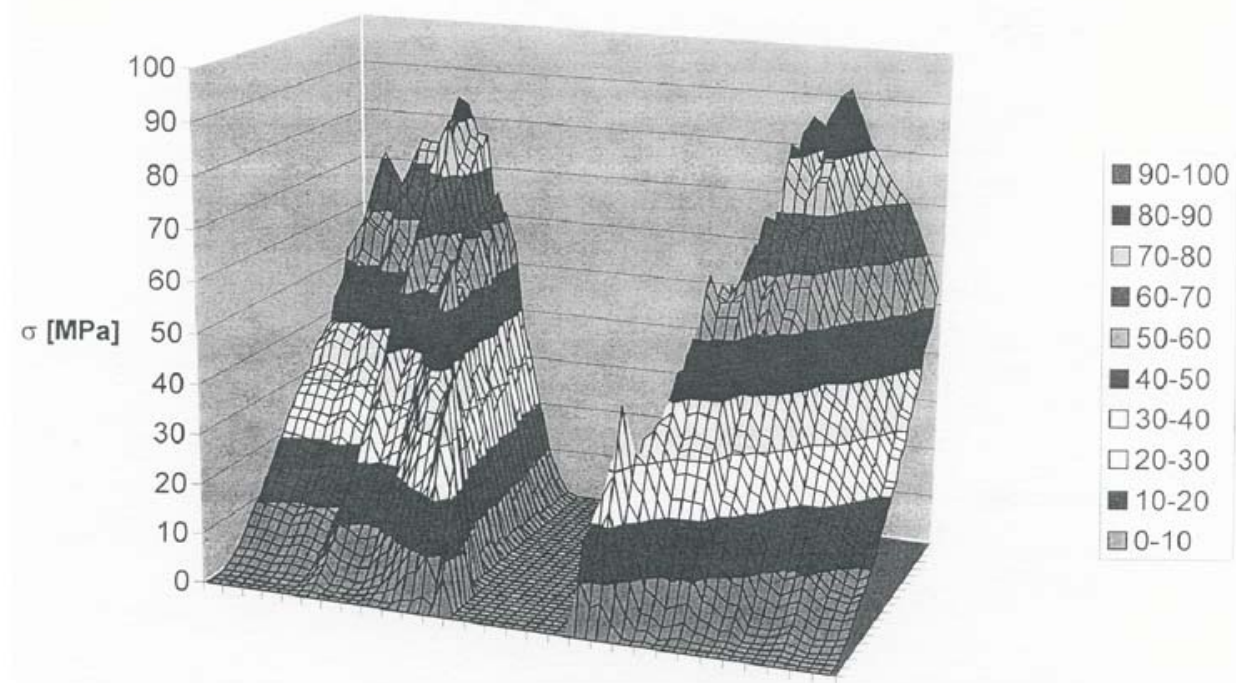

Fig. 3: Loading of the coal seam during test VW 21 in axonometry

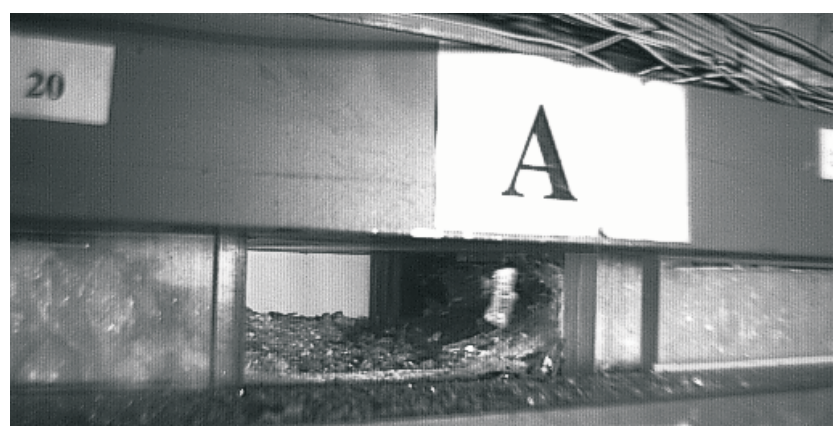

Photo 3: State before bump

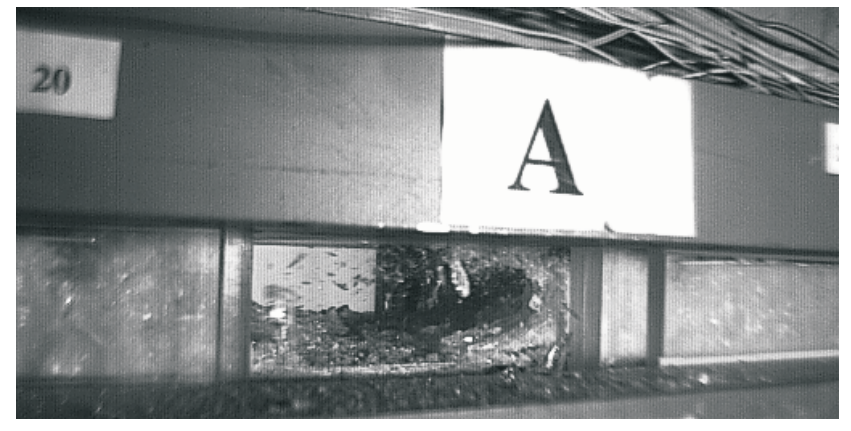

Photo 4: First extrusions appear

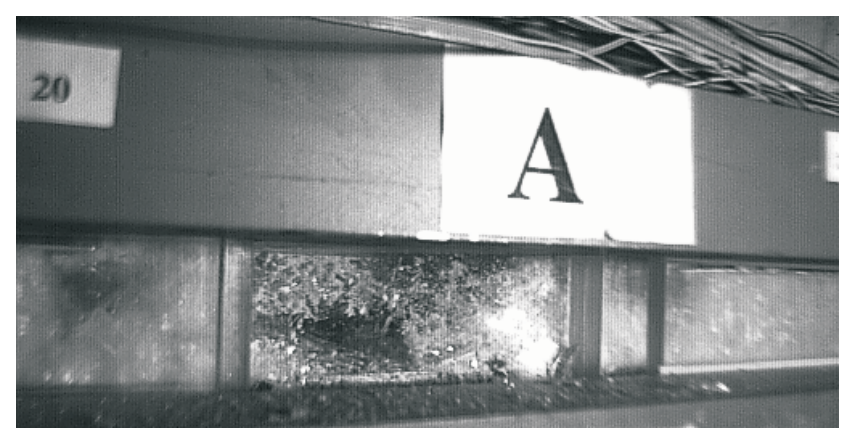

Photo 5: Early stage of bump

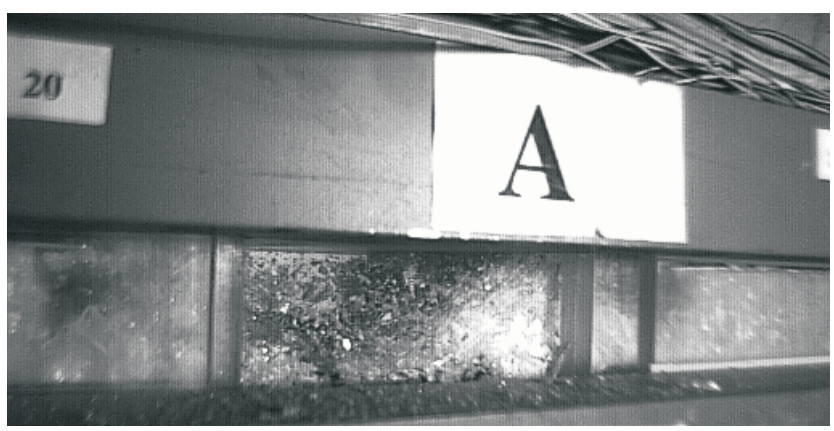

Photo 6: Late stage of bump

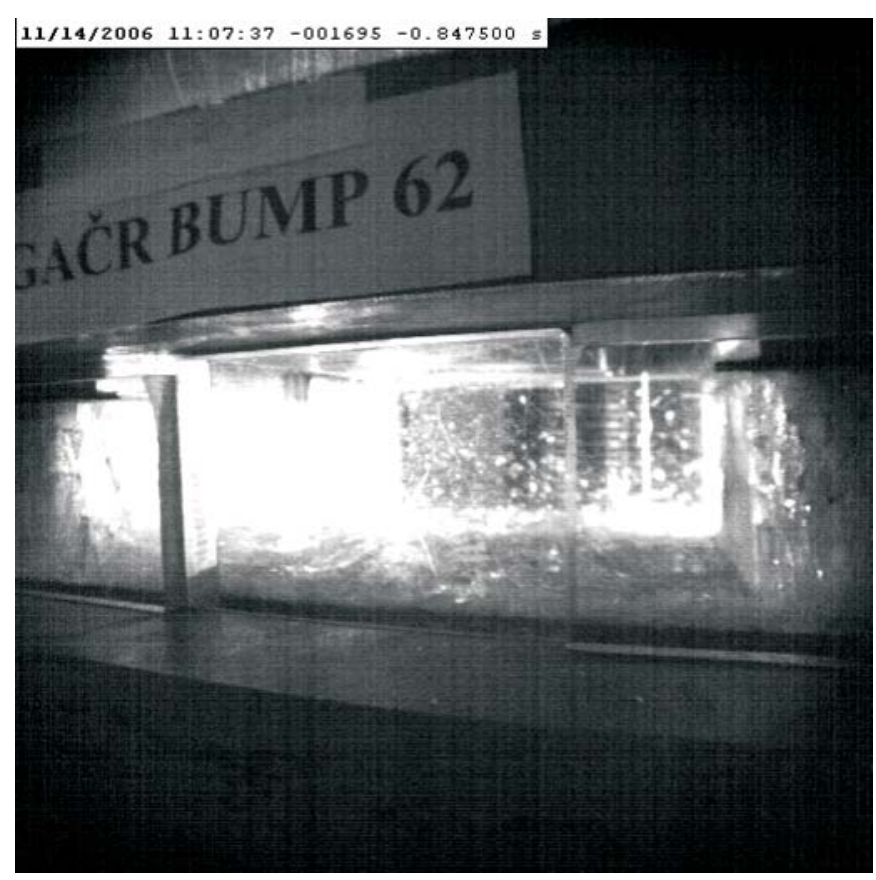

Photo 7: Bursting $(t=0.060 \mathrm{~s})$

(C) Czech Technical University Publishing House http://ctn.cvut.cz/ap/ 


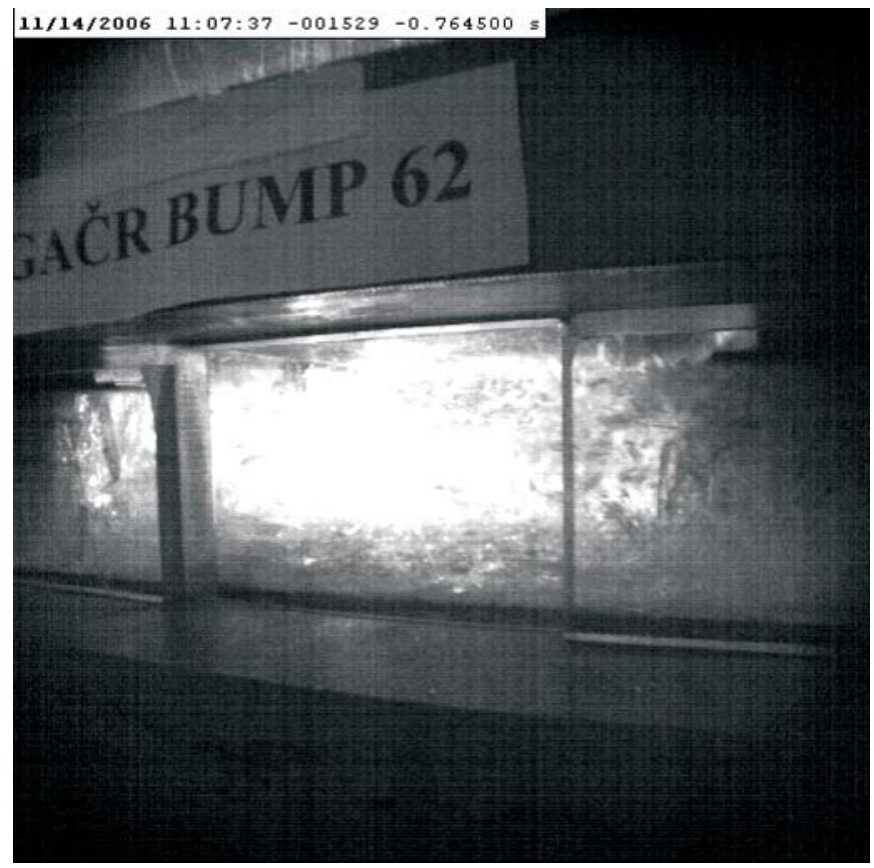

Photo 8: First wave of bump ( $t=0.146 \mathrm{~s})$

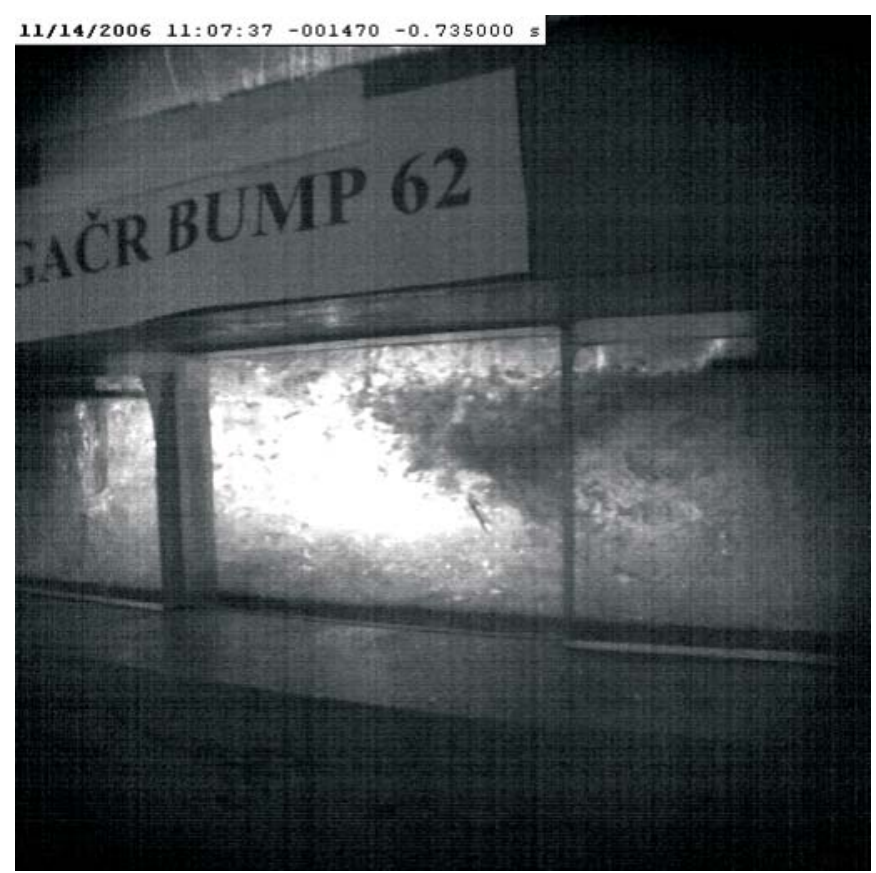

Photo 9: Second wave of bump $(t=0.178 \mathrm{~s})$

\subsubsection{Mechanics of bumps}

The last part of the experiments were also recorded with a high-speed camera. This made it possible to watch the bumps as events lasting several seconds. Photos 3-6 were chosen from the continuous records. They show that the bump started (like an earthquake) with a small extrusion of rock mass, see Photo 3, followed by the main bump, Photo 4 and 5 , and the state after the bump finished, Photo 6. The event sometimes ends with small extrusions of rock, thought not in the case described here.

\subsubsection{What the tests showed}

- The extruded rock mass is located on the only narrow strip next to the free rock surface. The breadth of this strip was only $15-40 \%$ of the height of the coal seam, and was proportionate to the bump force. The bigger the bump, the broader was the amount of extruded rock. The height of the coal seam was $70 \mathrm{~mm}$ in the experiment; the bump extruded approximately 10 to $30 \mathrm{~mm}$ of rock. After the bump, the surface of the coal was not smooth, it was uneven.

- In one case (out of about 30 cases) the bump came in two waves, see Photos 7-9.

- Bumps in experimental conditions last about $20 \mathrm{~ms}$, (the two-wave bump lasted $50 \mathrm{~ms}$ ), and whole events last about $0.5 \mathrm{~s}$.

- The time, between the first extrusion and the bump was 20-200 ms.

- A great amount of energy is released during the bump. Part of it extrudes the rock mass to an open space, and reaction forces strike the rest of the rock. This creates new joints in the rock and the bump does not continue. When the bump is only weak, no joints appear in non-destroyed rock, and the second wave of bump comes, see Photos 7-9.

- The speed of the load considerably influences the rock burst intensity. While the intensity is rather low for the slow experiments, and the number of bursts is smaller $(\sim 3)$ and in the intermediate experiments the bursts are stronger and their number increases to about 5 , for the fast experiments we also observe $\sim 5$ bursts, but of exceptionally high intensity. One of these bursts even damaged our experimental equipment - completely destroying the plexiglass sidings.

\section{Mathematical model}

$P F C^{2 D}$ (Particle Flow Code in Two Dimensions), developed by Itasca, USA, was used for the numerical modelling part of the project. A physical problem concerning the movement and interaction of circular particles may be modelled directly by $P F C^{2 D}$. $P F C^{2 D}$ models the movement and interaction of circular particles by the Distinct Element Method (DEM), as described by Cundall and Strack (1979).

Particles of arbitrary shape can be created by bonding two or more particles together. These groups of particles act as autonomous objects, provided that their bond strength is high. As a limiting case, each particle may be bonded to its neighbour. The resulting assembly can be regarded as a "solid" that has elastic properties and is capable of "fracturing" when the bonds break in a progressive manner. $P F C^{2 D}$ contains extensive logic to facilitate the modelling of solids as close-packed assemblies of bonded particles; the solid may be homogeneous, or it may be divided into a number of discrete regions of blocks.

The calculation method is a time stepping, explicit scheme. Modelling with $P F C^{2 D}$ involves the execution of many thousands of time steps. At each step, Newton's second law (force $=$ mass $\times$ acceleration) is integrated twice for each particle to provide updated velocities and new positions, given a set of contact forces acting on the particle. Based on 
Table 1: Material properties of the coal, overburden and walls

\begin{tabular}{|l|c|c|c|c|c|c|}
\hline Material & friction & kn & ks & density & n_bond & s_bond \\
\hline coal & 0.7 & $1 \mathrm{e} 10$ & $1 \mathrm{e} 10$ & 1900 & $1 \mathrm{e} 4$ & $1 \mathrm{e} 4$ \\
\hline joint planes & 0.1 & - & - & - & $1 \mathrm{e} 2$ & $1 \mathrm{e} 2$ \\
\hline overburden & 0.7 & $1 \mathrm{e} 10$ & $1 \mathrm{e} 10$ & 2300 & $2 \mathrm{e} 5$ & $2 \mathrm{e} 5$ \\
\hline walls & 1.0 & $1 \mathrm{e} 12$ & $1 \mathrm{e} 12$ & - & - & - \\
\hline
\end{tabular}

We used the following main material properties to get the required behavior:

- friction - friction coefficient of ball or wall surface (not friction angle)

- kn - normal stiffness of ball or wall when in contact with other balls [force/displacement]

- ks - shear stiffness of ball or wall when in contact with other balls [force/displacement]

- density - density of ball material [mass/volume]

- s_bond - shear contact bond strength [force]

- n_bond - normal contact bond strength [force]

these new particle positions, contact forces are derived from the relative displacements for pairs of particles: a linear or non-linear force/displacement law at the contacts may be used.

Model parameters: In order to model rock bursting in a coal mine gallery we created a 2D box in the computer and filled the upper part with larger overload particles (balls, 100 rows) and the lower part with smaller coal balls (50 rows).
The gallery was simulated by a rectangular opening in the lower part of the box (see Figs. 4-8). In the coal we set up joint planes at 45 degrees to horizontal. The material properties were set to model known coal mine data (cf. Table 1), with a time step of $0.00001 \mathrm{~s}$. The loading was simulated by moving the top wall of the box downwards at a fixed speed at the beginning of the simulation (8000 steps). After the loading we typically performed about 200000 integration steps (2 s) to

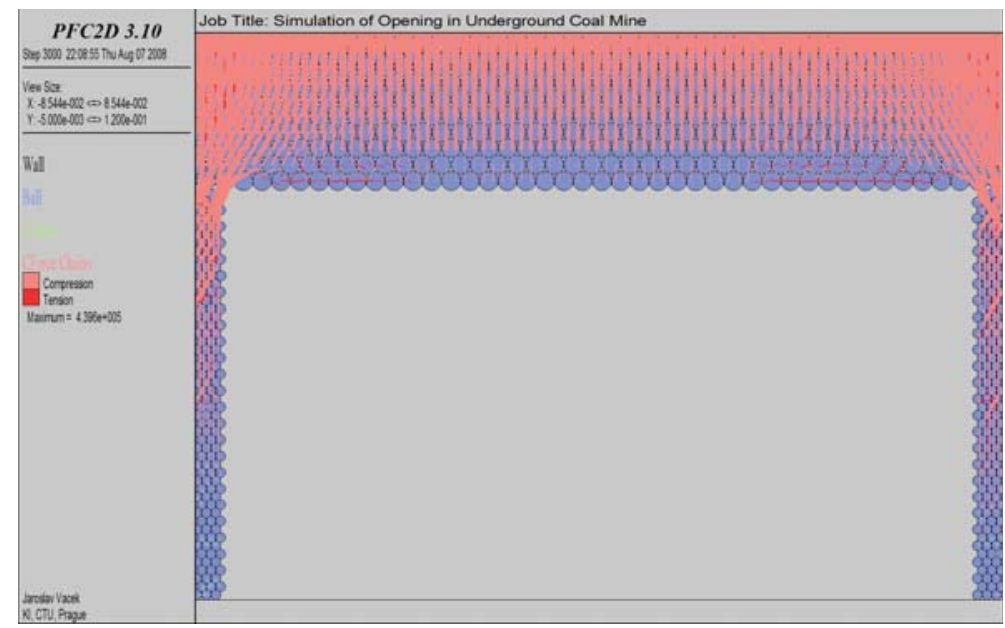

Fig. 4: Mathematical model before the bump

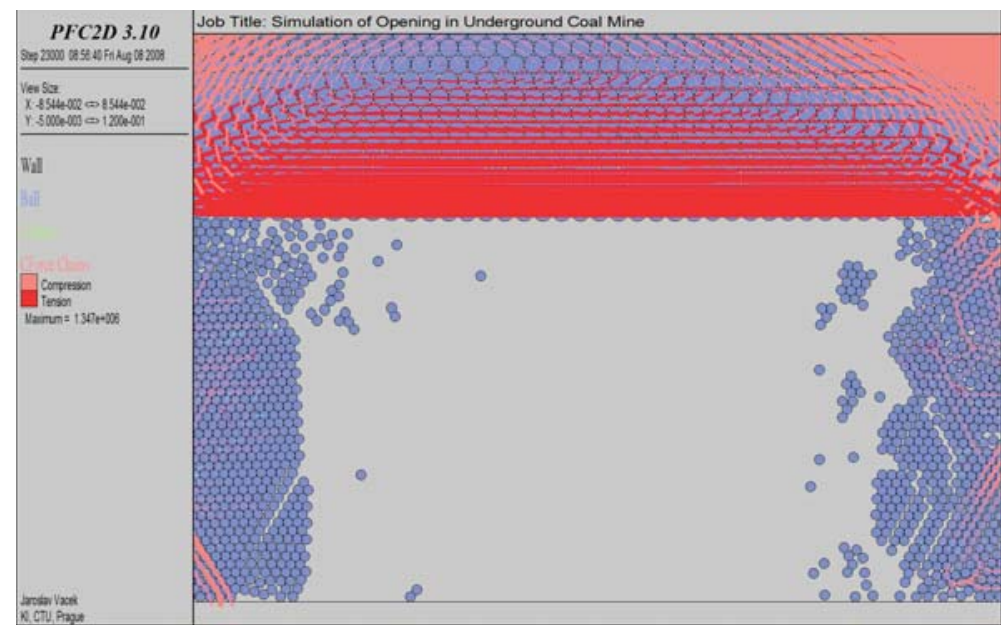

Fig. 5: The first stage of the bump 


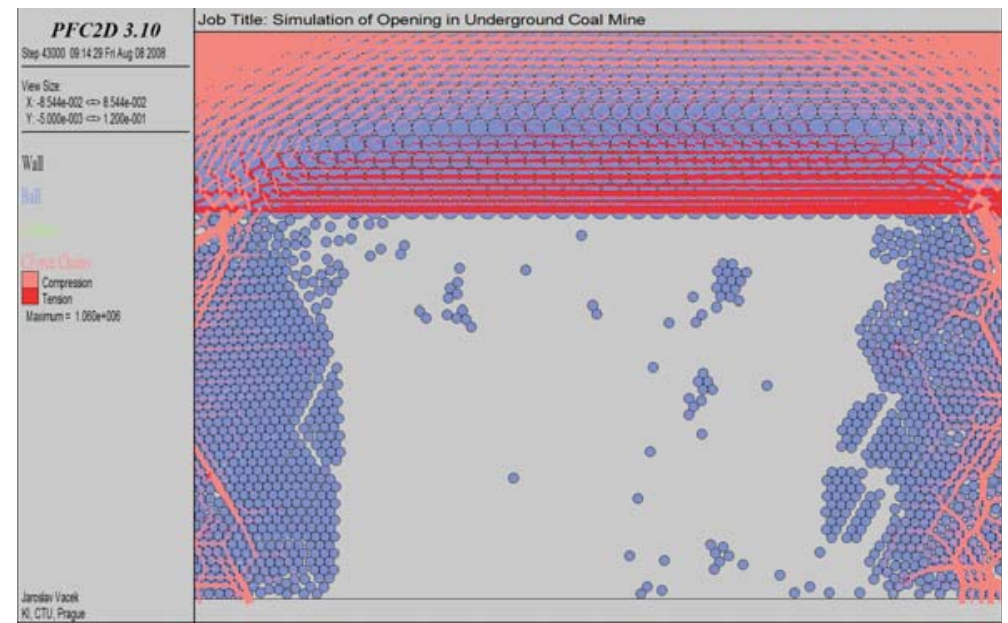

Fig. 6: Next stages of the bump

let the dynamics evolve. The bursting started rather early $(0.1 \mathrm{~s})$. Several simulations with varying numbers of coal particles and other parameters were performed with no significant impact on the qualitative results of the simulations.

Figs. 4-8 show details of the mathematical model of the bump, and Fig. 9 shows the typical stress distribution along the coal mine. The stress grows (I, II) until the first bump initiation (III). This occurs in the $5^{\text {th }}$ measurement cycle approximately, then the stress decreases in this location, but it increases simultaneously in the $7^{\text {th }}$ measurement cycle, when the second bump initiation occurs (IV). Subsequent bump initiations can be expected in the $8^{\text {th }}$ and $10^{\text {th }}$ measurement cycles (V, VI).

\section{Conclusion}

A combination of experimental and mathematical models appears very appropriate for a study of the stress distribution

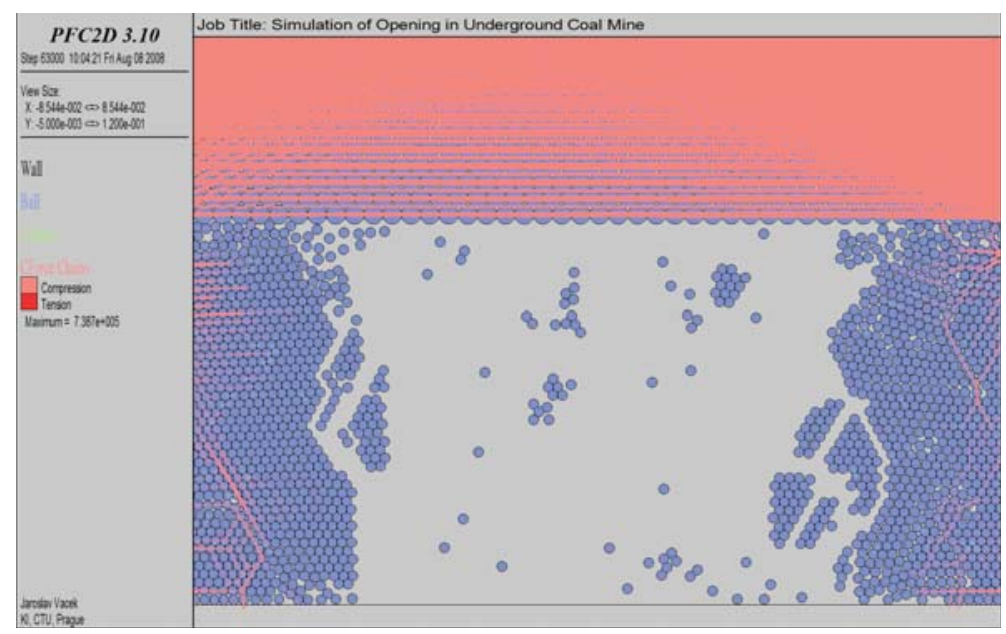

Fig. 7: Next stages of the bump

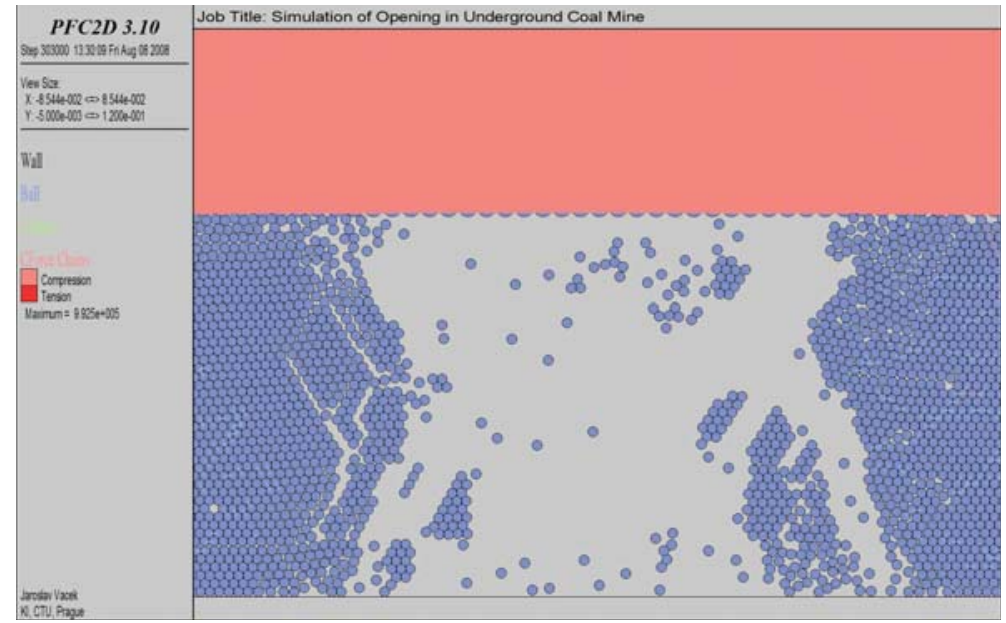

Fig. 8: Late stage of the bump 


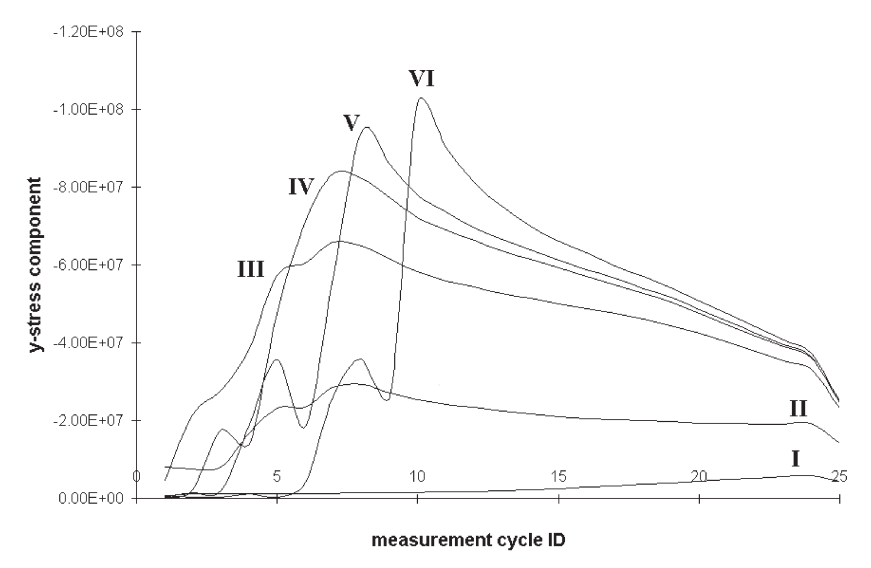

Fig. 9: Stress distribution along the coal seam

$$
\begin{aligned}
& \text { I - } 5000 \text { cycles, } \\
& \text { II - } 7000 \text { cycles, } \\
& \text { III - } 9000 \text { cycles, } \\
& \text { IV - } 12000 \text { cycles, } \\
& \text { V - } 15000 \text { cycles, } \\
& \text { VI - } 26000 \text { cycles }
\end{aligned}
$$

in a coal seam before and after rock burst initiation. Both methods enable a time dependent study of the problem, and enable us to study the development of cracks during rock burst initiation, and then extrusion of material into an open space during a burst. Thus they offer a description of the problem that is very close to reality.

\section{Acknowledgement}

This research and this paper have been supported by the Grant Agency of the Czech Republic, (GAC̆R), grant number 103 / 08 / 0922 "Influence of shock and impact loading on structures" and European Commission project MCRTN-CT-2005-019481 "From FLIM to FLIN".

\section{References}

[1] Foss, M. M., Westman, E. C.: Seismic Method for in-seam coal mine ground control problems. SEG International Exposition and $64^{\text {th }}$ Annual Meeting, Los Angeles, 1994, p. 547-549.

[2] Goodman, R. E.: Introduction to Rock Mechanics, John Wiley \& Sons, 1989, 562 p.

[3] Torańo, J., Rodríguez, R., Cuesta, A.: Using Experimental Measurements in Elaboration and Calibration of
Numerical Models in Geomechanics. Computation Methods and Experimental Measurements X, Alicante, 2001, p. 457-476.

[4] Vacek, J., Procházka, P.: Rock Bumps Occurrence during Mining, Computation Methods and Experimental Measurements X, Alicante, 2001, p. 437-446.

[5] Vacek J., Bouška, P.: Stress Distribution in Coal Seam before and after Bump Initiation. Geotechnika 2000, Glivice- Ustroň, 2000, p. 55-66.

[6] Vacek, J., Procházka, P.: Behaviour of Brittle Rock in Extreme Depth. $25^{\text {th }}$ Conference on Our World in Concrete $\mathcal{E}^{\circ}$ Structures, Singapore, 2000, p. 653-660.

[7] Williams, E. M., Westman, E. C.: Stability and Stress Evaluation in Mines Using In-Seam Seismic Methods. $13^{\text {th }}$ Conference on Ground Control in Mining, US Bureau of Mines, 1994, p. 290-297.

[8] Šňupárek, R., Zeman, V: Rockbursts in Longwall Gates during Coal Mining in Ostrava-Karviná Basin. Eurock 2005 Impact of Human Activity on the Geological Environment, Balkema 2005, p. 605-610.

[9] Konečný, P., Velička, V., Šňupárek, R., Takla, G., Ptáček, J.: Rockbursts in the Period of Mining Activity Reduction in Ostrava-Karviná Coalfield, $10^{\text {th }}$ Congress of the ISRM Technology, Johannesburg, 2003, p. 665-668.

Prof. Ing. Jaroslav Vacek, DrSc.

Phone: +420 224353549

e-mail:vacek@klok.cvut.cz

Czech Technical University in Prague

Klokner Institute

Šolínova 7

16608 Prague 6, Czech Republic

RNDr. Jaroslav Vacek, Ph.D.

phone: +420220183103

e-mail:vacek@eefus.colorado.edu

RNDr. Jana Choholoušová, Ph.D.

phone: +420220183216

e-mail.jana@eefus.colorado.edu

Institute of Organic Chemistry and Biochemistry Academy of Sciences of the Czech Republic

Flemingovo nám. 2

16610 Prague 6, Czech Republic 